\title{
Estimated Binding Energies of Drug-Like and Nondrug-Like Molecules in the Active Site of HIV-1 Integrase, 1BIS.pdb, and Two Mutant Models: Y143R and N155H
}

\author{
Julie B. Ealy*, Noorhaan Abouomar, Justin Cogan, Paolo Flauta, Liliana Nassar, \\ Matthew Mekolochik, Sarah Ramzy, Christopher Shannon, Habib Yazgi \\ Penn State Lehigh Valley, Center Valley, PA, USA \\ Email: ${ }^{*}$ jbe10@psu.edu
}

How to cite this paper: Ealy, J.B., Abouomar, N., Cogan, J., Flauta, P., Nassar, L., Mekolochik, M., Ramzy, S., Shannon, C., Yazgi, H. and Nassar, L. (2017) Estimated Binding Energies of Drug-Like and Nondrug-Like Molecules in the Active Site of HIV-1 Integrase, 1BIS.pdb, and Two Mutant Models: Y143R and N155H. Advances in Bioscience and Biotechnology, 8, 163183.

https://doi.org/10.4236/abb.2017.85013

Received: March 29, 2017

Accepted: May 23, 2017

Published: May 27, 2017

Copyright $\odot 2017$ by authors and Scientific Research Publishing Inc. This work is licensed under the Creative Commons Attribution International License (CC BY 4.0).

http://creativecommons.org/licenses/by/4.0/

\section{c) (i) Open Access}

\begin{abstract}
Lipinski's "Rule of Five" was introduced for predicting oral bioavailability to describe drug-like molecules. For the purpose of this research the rules were used to separate potential inhibitors of HIV-1 integrase (1BIS.pdb) into two groups: drug-like and nondrug-like. If one of Lipinski's "Rule of Five" was not followed the potential inhibitor was classified as nondrug-like. Thirty molecules were identified from the literature, twenty-four drug-like and six nondrug-like, that were docked into the active site of 1BIS.pdb (considered the non-mutated protein) and two mutant models, Y143R and N155H. These are two of the mutations that have led to increased resistance to HIV-1 integrase drugs such as raltegravir and elvitegravir. The computational software, ICMPro (Molsoft L.L.C.), was used to determine the estimated binding energy (EBE) of the drug/protein complex. It was found that the nondrug-like molecules generally had a more negative EBE, that is, tighter binding with 1BIS. $\mathrm{pdb}$, though there were several exceptions in the drug-like group. With the protein mutant model Y143R, the majority of drug-like (58\%) and nondruglike molecules $(67 \%)$ had tighter binding. However, for the mutant model $\mathrm{N} 155 \mathrm{H}$, there was the same percent $(46 \%)$ of drug-like molecules with tighter binding with the mutant model as with 1BIS.pdb. The drug-like molecules were used when there was a $\geq 1 \mathrm{kcal} /$ mole difference between $1 \mathrm{BIS}$.pdb and either of the two mutant models to suggest a pharmacophore with structural characteristics for an HIV-1 integrase inhibitor.
\end{abstract}

\section{Keywords}

Lipinski's "Rule of Five", Drug-Like and Nondrug-Like Molecules, HIV-1 Integrase, Estimated Binding Energy, Pharmacophore 


\section{Introduction}

The Centers for Disease Control and Prevention (CDC) in Healthy People 2020 addressed 10-year national objectives to improve the health of Americans. Of the 600 objectives that cover 42 topic areas, 18 of the objectives focus on HIV and the acquired immunodeficiency syndrome (AIDS). The primary goal of Healthy People 2020 as it relates to HIV/AIDS is to prevent HIV infection and its related illness and death [1]. As of 2015, there are approximately 39,515 new HIV infections each year in the United States [2]. Thus, interventions are needed to prevent transmission to those who are uninfected, and optimized treatment is necessary for those who are already infected. The development of new drugs that can prevent transmission as well as disease progression is of paramount public health importance, and targeting a critical viral enzyme such as HIV-1 integrase is a proven approach to meet this need.

Integrases [3] are enzymes that are packaged into retroviral particles, such as those of the human immunodeficiency virus (HIV-1) along with reverse transcriptase (RT) and the viral ribonucleic acid (RNA) genome. Integrase enzymes catalyze the insertion of the DNA copy of the viral genome synthesized by the RT into a host chromosomal locus to produce a lifelong infection of the host. The clinical development of existing HIV-1 integrase inhibitors or drugs has demonstrated the power of targeting integrase activity as a therapeutic approach [3] [4] [5] [6].

A simplified model of a drug binding to the active site of a large molecule such as a protein is shown in Figure 1. When a drug binds to the active site, the estimated binding energy can be computationally calculated from the energy considerations of the different interactions between the drug and the protein.

\section{HIV-1 Life Cycle}

HIV enters the cell and reverse transcriptase-one of three enzymes involved in the life cycle of HIV-copies single-stranded RNA (HIVRNA) into double stranded viral DNA (DS-cDNA). Integrase, the second of three enzymes, integrates the viral DNA into the host cell's DNA (HostDNA). The last enzyme, protease, is responsible for cleavage of polyproteins into the structural proteins of HIV such as the matrix, capsid, and nucleocapsid proteins. The mature HIV-1 virion exits the cell. (Figure 2) [7]

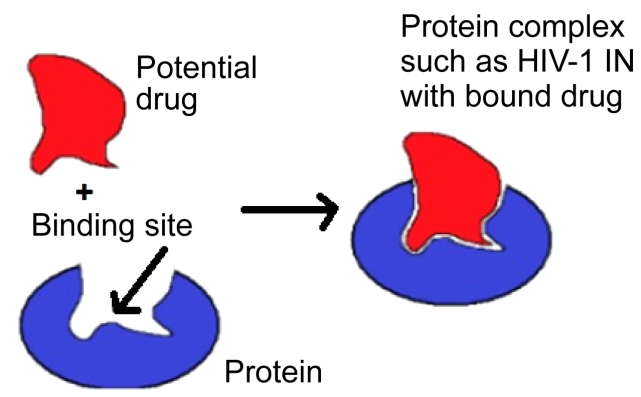

Figure 1. A simple representation of binding. 


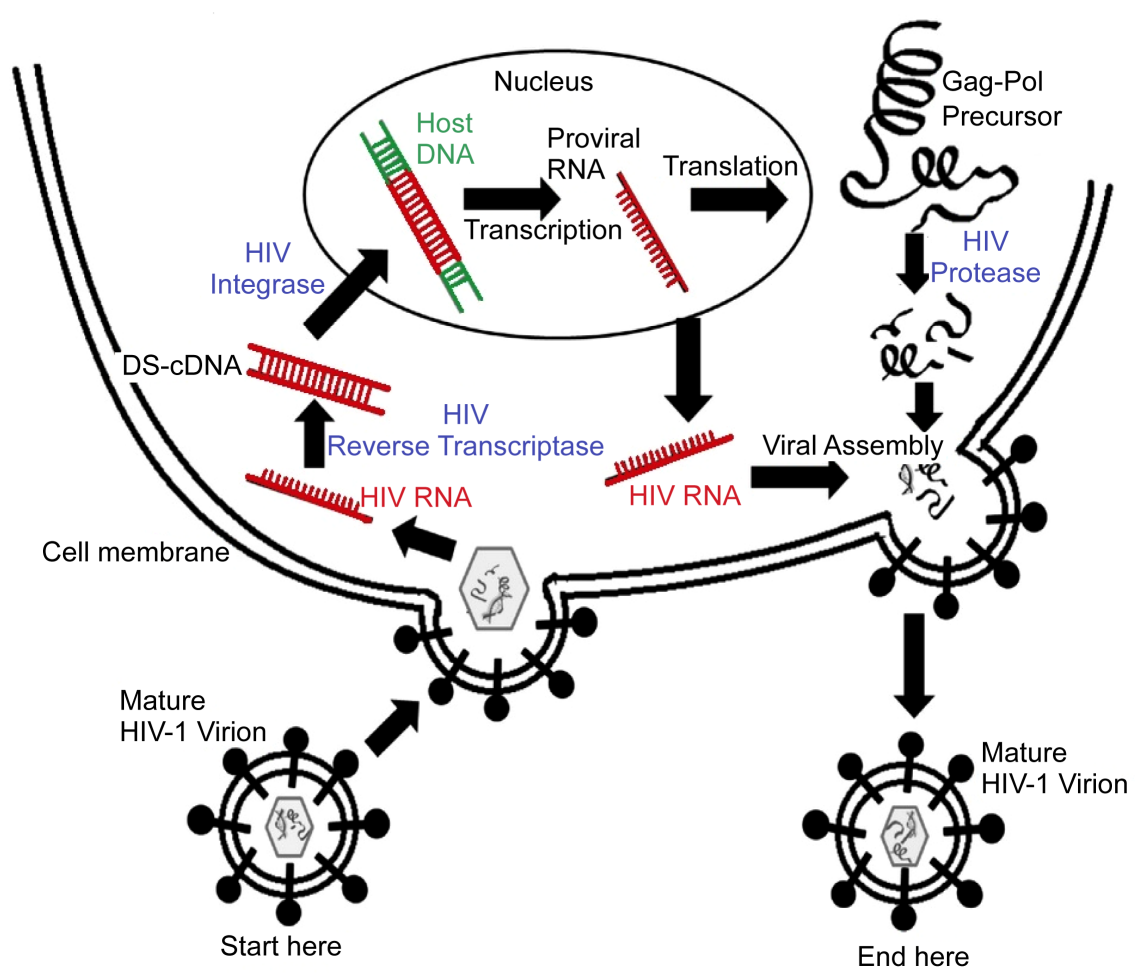

Figure 2. HIV life cycle.

https://cellandbioscience.biomedcentral.com/articles/10.1186/2045-3701-2-32.

\section{HIV-1 Integrase Structure and Function}

HIV-1 integrase consists of three domains or sections: amino-terminal domain, amino acids 1 - 50 (NTD), core catalytic domain, 50 - 212 (CCD), and the carboxyl-terminal, 212 - 288 (CTD) [8].

The catalytic core domain of 1BIS.pdb [9] was the focus of the research (Figure 3). It contains the active site of the protein that is defined by the amino acids: aspartic acid (D) 64, aspartic acid (D) 116, and glutamic acid (E) 152-the DDE triad [10]. Using ICM-Pro [11], computational software, several pockets were identified but one of the pockets included the active site amino acids, and therefore a binding site for potential drugs. The figure was generated using ICM-Pro, Molsoft, L.L.C.

HIV-1 integrase catalyzes two biologically relevant nicking reactions (Figure 4): The first reaction (1) (referred to as $3^{\prime}$ processing) nicks and trims the $3^{\prime}$ end of each strand of unintegrated viral DNA at a specific site. The second reaction (2) (referred to as strand transfer) (ST) inserts the trimmed ends of viral DNA into the two strands of cellular DNA [12].

\section{Drug-Like and Nondrug-Like Molecules/Inhibitors}

Many inhibitors have drug-like properties that follow Lipinski's "Rule of Five" that was introduced for predicting oral bioavailability [13].

These rules include the following:

1) Molecular mass $\leq 500 \mathrm{~g} / \mathrm{mole}$, 


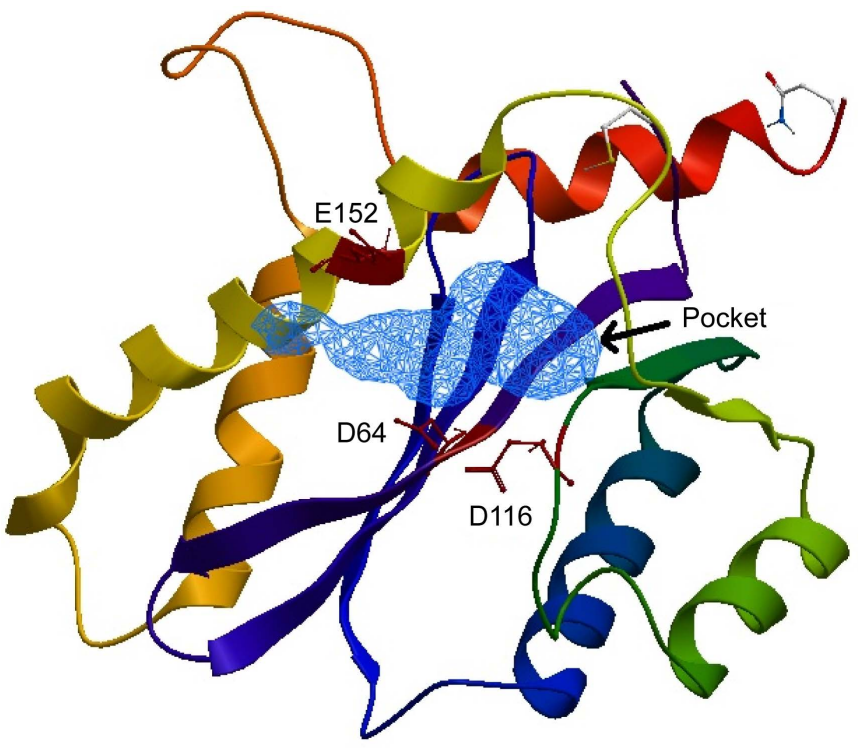

Figure 3. The catalytic core domain of 1BIS.pdb.

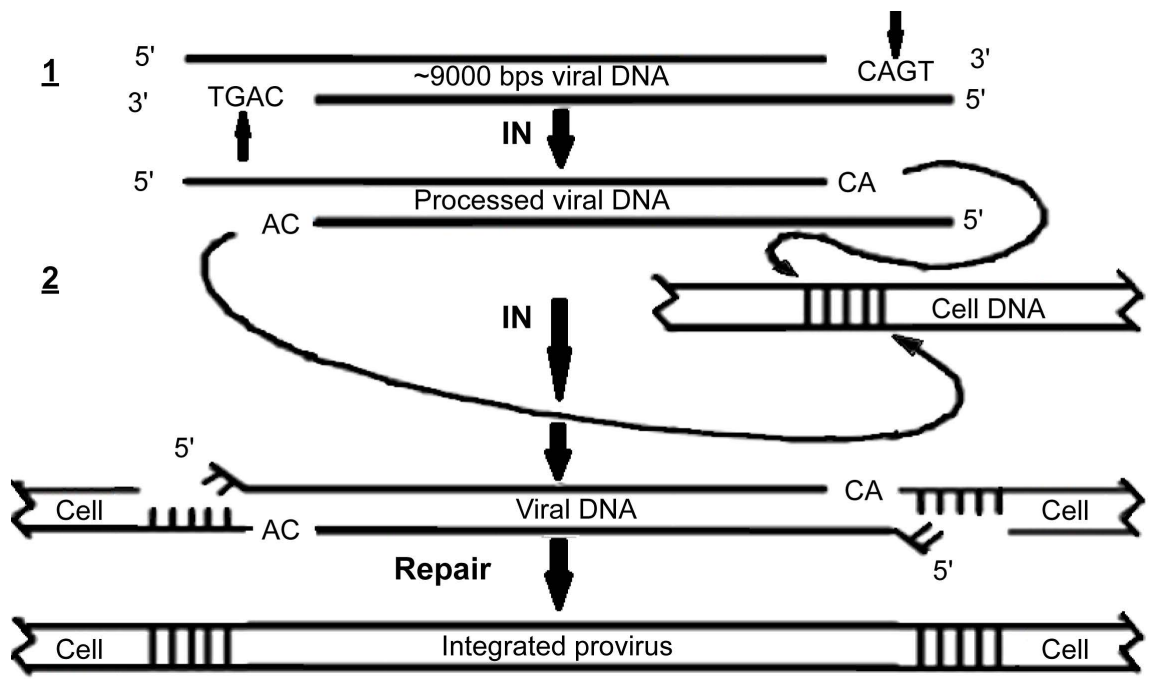

Figure 4. The two nicking reactions of HIV-1 integrase (figure provided by Dr. Michael Katzman, Penn State Hershey Medical Center).

2) $\log P$ (the partition coefficient, defined as the ratio of the concentration of a drug in octanol to its concentration in water) between \pm 5 ,

3) Hydrogen bond donors $\leq 5$, and

4) Hydrogen bond acceptors $\leq 10$.

Some integrase inhibitors, however, do not follow these rules. For this research, if an inhibitor failed to follow even one of these rules it was classified as nondrug-like. Using data from ICM-Pro, the inhibitors were divided into two groups-drug-like and nondrug-like.

Figure 5 and Figure 6 (generated using ICM-Pro, Molsoft L.L.C.) represent an example of a drug-like [14] and nondrug-like molecule [14], respectively. The molecules were docked into the active site of 1BIS.pdb [9] and are shown in the potential binding site pocket identified by ICM-Pro. The parameters for Lipinski's 
<smiles>[O]N1CC(C(=O)NCc2ccc(F)cc2F)=C(NCCO)c2cccnc21</smiles>

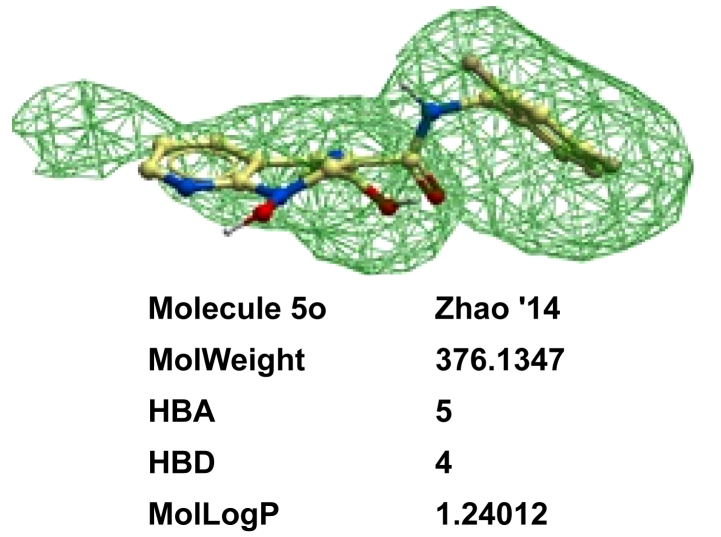

Figure 5. Zhao'14, 5o [14].

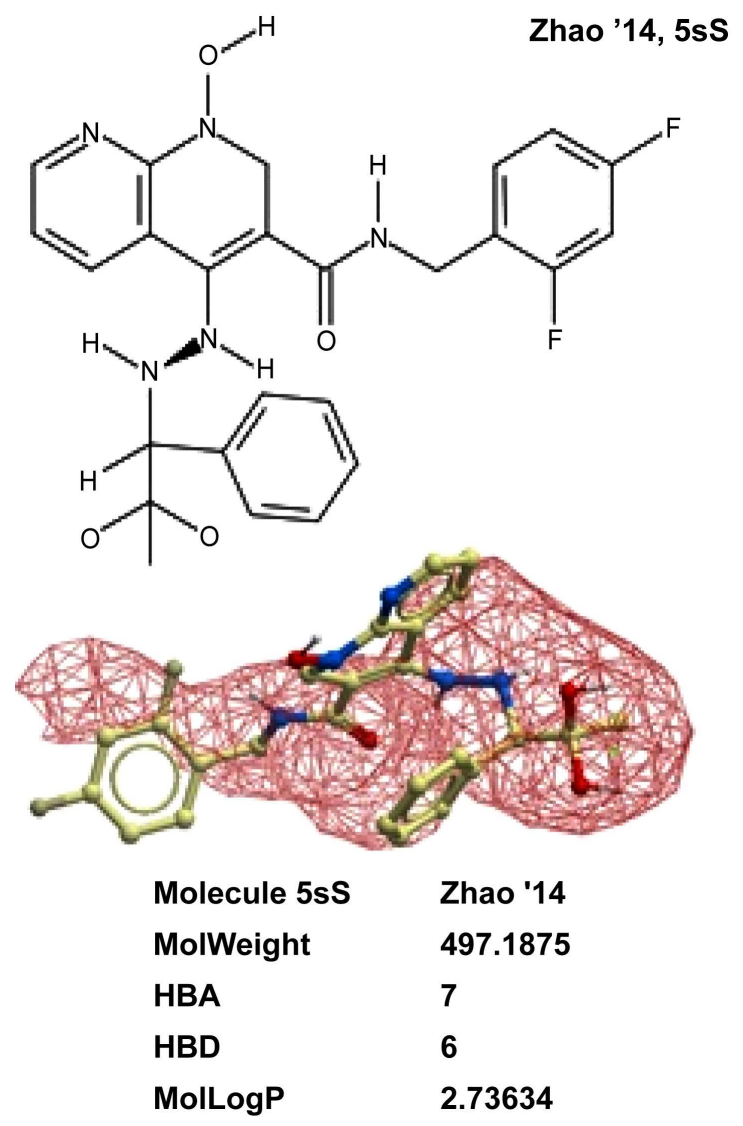

Figure 6. Zhao'14, 5sS [14]. 
"Rule of Five" [13] from ICM-Pro are shown for each molecule. The nondrug-like molecule, $5 \mathrm{~s} S$ has an unacceptable number of hydrogen bond donors (HBD), that is, six.

\section{Estimated Binding Energy}

For the research, the goal was to computationally determine and compare the estimated binding energy (EBE) of a group of drug-like and nondrug-like molecules using 1BIS.pdb and two mutant models of 1BIS.pdb [15], Y143R and N155H. An estimated binding energy can be determined using ICM-Pro (Molsoft, L.L.C.) The binding energy function of ICM-Pro takes into account the following terms [16]:

1) Weighted sum of ligand-target van der Waals interactions and the internal force field energy of the ligand,

2) Free energy changes due to conformational energy loss upon ligand binding,

3) Hydrogen bonding interactions,

4) Hydrogen bond donor-acceptor desolvation energy,

5) Solvation electrostatic energy upon ligand binding,

6) Hydrophobic free energy gain, and

7) Size correction term proportional to the number of ligand atoms.

The more negative the ICM-Pro score, the higher the probability the ligand is a binder and could act as a potential drug to block the action of a protein such as HIV-1 integrase. Therefore, the viral DNA could be prevented from integration into the host's DNA.

\section{The Molecules}

From previous research on approximately 200 molecules, initially considered to be potential inhibitors of HIV-1 integrase, a decision was made to address the EBE of a small group of molecules. Molecules with an experimental strand transfer concentration $\leq 0.01 \mu M$ were chosen because strand transfer is the reaction where HIV-1 integrase inserts the trimmed ends of viral DNA into the two strands of cellular DNA [12]. The smaller the concentration of a drug that is needed to inhibit the integration of viral DNA into host DNA, that is, strand transfer, the fewer the side effects of the drug. Only 30 molecules remained from the 200 considered initially, twenty-four drug-like and six nondrug-like molecules. Figures 7-9 show the drug-like molecules, and Figure 10, the nondruglike molecules.

\section{Method}

Each molecule was docked a minimum of three times within an 8 - $\AA$ radius of the potential binding site pocket. A $2 \mathrm{D}$ ligand interaction of molecule $5 \mathrm{~s} S$ [14] is displayed in Figure 11. It represents the interaction of the molecule with the surrounding amino acids of 1BIS.pdb within an 8 - $\AA$ radius. 


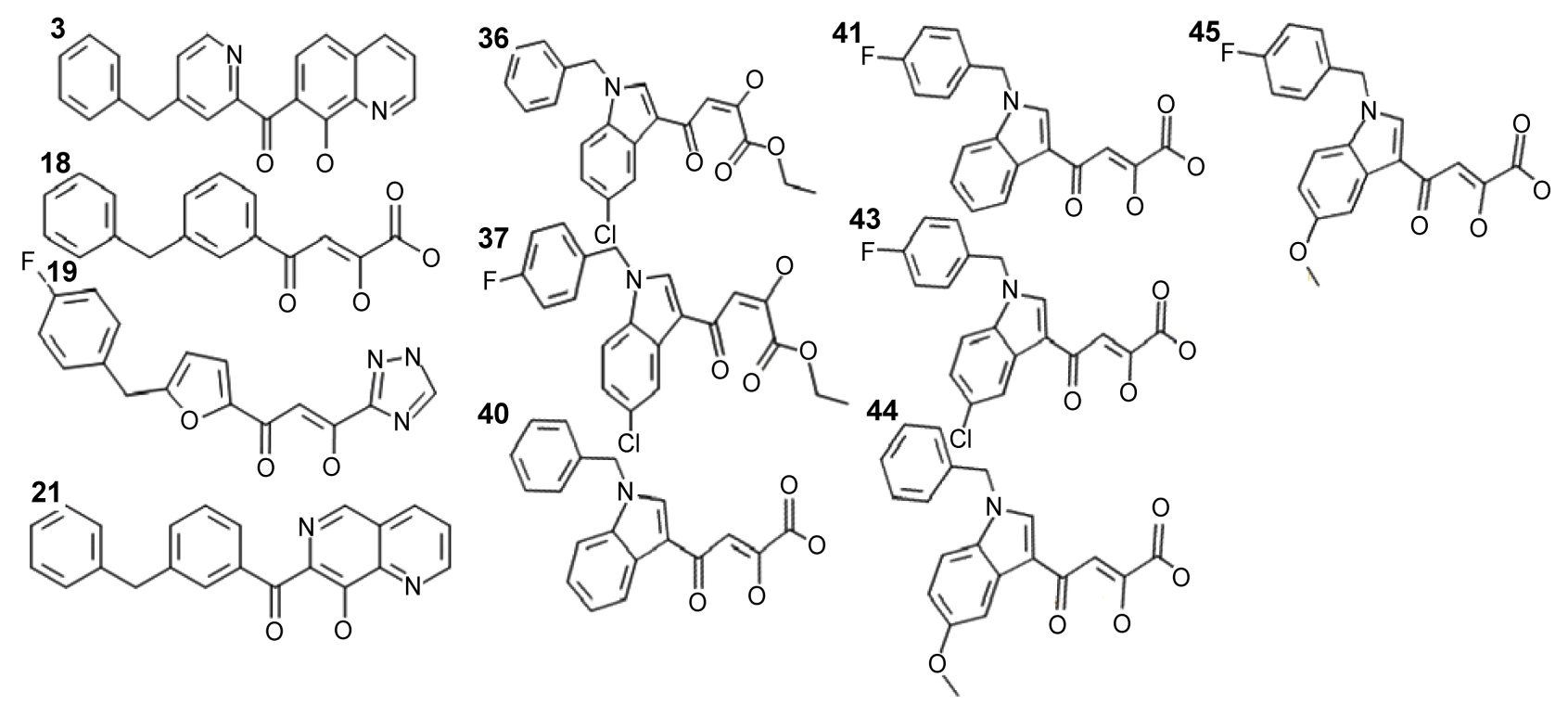

Figure 7. Drug-like molecules with an experimental ST $\leq 0.01 \mu \mathrm{M}$; Barreca'05 [17].<smiles>O=C(NCc1ccc(F)cc1F)c1c(Nc2ccccc2)c2cccnc2n(O)c1=O</smiles><smiles>CCCCCC1C(C(=O)NCc2ccc(F)cc2F)=C(O)N(O)c2ncccc21</smiles><smiles>CC(CCO)C1=C(C(=O)NCc2ccc(F)cc2F)CN(O)c2ncccc21</smiles><smiles>CNC1=C(C(=O)NCc2ccc(F)cc2F)CN(O)c2ncccc21</smiles><smiles>CC(C)(C)NC1=C(C(=O)NCc2ccc(F)cc2F)CN(O)c2ncccc21</smiles><smiles>CC(=O)OCCNC1=C(C(=O)NCc2ccc(F)cc2F)CN(O)c2ncccc21</smiles><smiles>CN(C)C1=C(C(=O)NCc2ccc(F)cc2F)CN(O)c2ncccc21</smiles><smiles>O=C(NCc1ccc(F)cc1F)C1=C(NCNc2ccccc2)c2cccnc2N(O)C1</smiles><smiles>NC1=C(C(=O)NCc2ccc(F)cc2F)CN(O)c2ncccc21</smiles>

Figure 8. Drug-like molecules with an experimental ST $\leq 0.01 \mu \mathrm{M}$; Zhao'14 [14].

An average EBE was recorded. However, after docking and before computational determination of the EBE, the best conformer provided by ICM-Pro was chosen based on using crystal structures from the Cambridge Structural Database [19]. The exact molecules were not found in the Cambridge Structural Database, but from communication with a computational chemist at Bristol Myers Squibb [20], it was suggested that a combination of two to three molecules might be needed to determine the best conformer. For the majority of molecules the first conformer provided by ICM-Pro was the one used to determine the EBE. 
<smiles>O=C(O)C(=O)CC(=O)c1cccc(Cc2ccccc2)c1</smiles>

4<smiles>Cc1c(C(=O)c2cccc(Cc3ccccc3)c2)ncc2cccnc12</smiles>

6<smiles>[2H]Oc1c(C(=O)c2cc(Cc3ccccc3)cc(C(=O)c3cc(Cc4ccccc4)cc(C(=O)c4cc(Cc5ccccc5)ccn4)c3O)c2)ncc2cccnc12</smiles>

Figure 9. Drug-like molecules with an experimental ST $\leq 0.01 \mu \mathrm{M}$; Zhuang'03 [18].

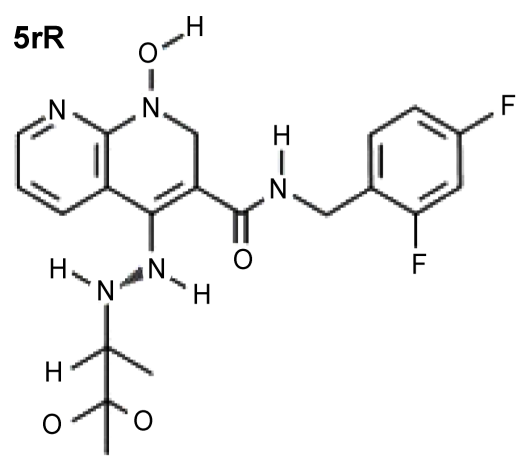<smiles>[R5]SON1CC(C(=O)NCc2ccc(F)cc2F)=C(N([2H])N([2H])[C@H](c2ccccc2)C(C)(O)O)c2cccnc21</smiles><smiles>[R]ON1CC(C(=O)NCc2ccc(F)cc2F)=C(N([2H])N[2H])c2cccnc21</smiles><smiles>CC(O)C(C)O</smiles><smiles>CC(O)C(C)N(N)NC1=C(C(=O)NCc2ccc(F)cc2F)CN(O)c2ncccc21</smiles><smiles>CC(O)C(c1ccccc1)N([TlH])N([IH])C1=C(C(=O)NCc2ccc(F)cc2F)CN(O)c2ncccc21</smiles><smiles>CC(O)(O)C(NN)C1=C(C(=O)NCc2ccc(F)cc2F)CN(O)c2ncccc21</smiles>

Figure 10. Nondrug-like molecules with an experimental ST $\leq 0.01 \mu \mathrm{M}$; Zhao'14 [14]

\section{Results of the Estimated Binding Energies with 1BIS.pdb}

\subsection{Drug-Like Molecules}

The estimated binding energy of the drug-like molecules [14] [17] [19] is shown in Figure 12. 


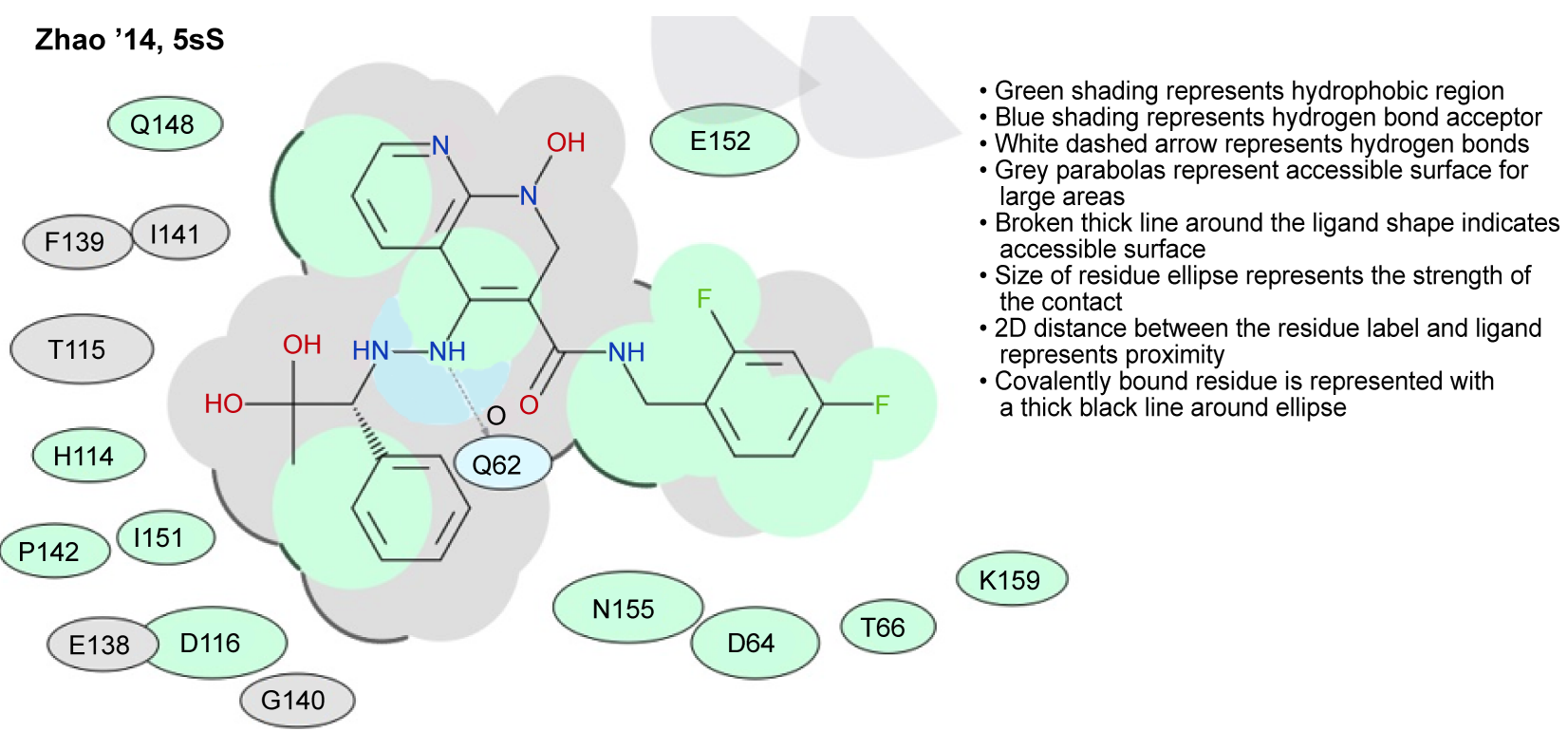

Figure 11. 2D ligand interaction of molecule $5 \mathrm{~s} S[14]$ within an 8 - $\AA$ radius of the active site. The figure was generated by Andy Orry, Molsoft, L.L.C.

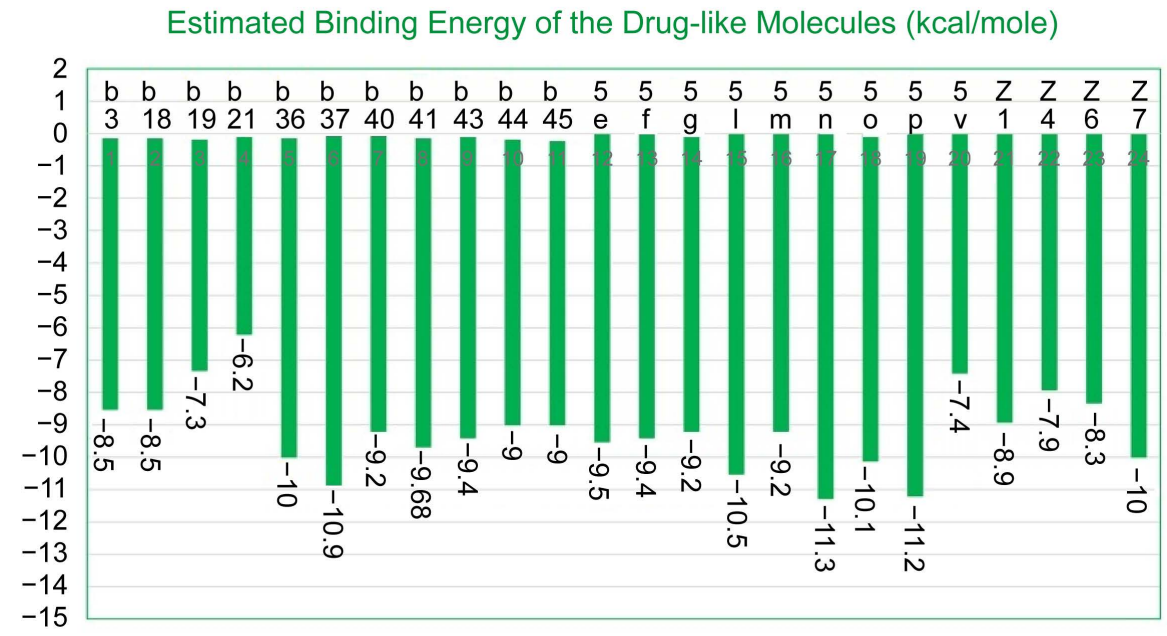

Figure 12. The estimated binding energies of the drug-like molecules with 1BIS.pdb. The numbers above the bars correspond to those in Figures 7-9.

\subsubsection{Barreca'05 [17] (Figure 7)}

Molecules 3 and 21 have a similar framework: aromatic ring, linker, aromatic ring, linker, and two aromatic fused rings [21]. The only difference is the location of a nitrogen in the ring. However, their EBE values are -8.5 and -6.2 , respectively. The placement of the nitrogen may account for the difference in the EBE. Molecule 18 is similar to molecule 3 but instead of two aromatic fused rings there is a sidechain [21]. They have the same EBE. Molecules 36, 37, 40, 41, 43,44 , and 45 have a similar framework: aromatic ring, linker, indole group, and a sidechain. Molecules 36 and 37 only differ in the presence of a fluorine on the first ring of molecule 37; they have a similar EBE. Molecules 40, 41, and 43 differ in the absence (molecule 40) or presence of fluorine and/or chlorine. They all have a similar EBE. Molecules 44 and 45 have a methoxy group as a sidechain off 
the benzene ring of the indole group but as in the previous three molecules, the presence of fluorine on molecule 45 does not appear to affect the EBE since they have the same EBE.

\subsubsection{Zhao'14 [14] (Figure 8)}

All of the Zhao drug-like molecules have a similar framework of two aromatic fused rings, an amide linker, aromatic ring, and a sidechain off the second ring that is different for each of the molecules. There appears to be stronger binding in $5 \mathrm{l}, 5 \mathrm{n}, 5 \mathrm{o}$, and $5 \mathrm{p}$; each of these molecules has a larger sidechain off the second ring.

\subsubsection{Zhuang'03 [18] (Figure 9)}

Molecules 4, 6, and 7 have a similar framework composed of an aromatic ring, a methyl group linker, aromatic ring, a carbonyl group linker, and two aromatic fused rings. Molecule 7 has a large sidechain off the second ring, that is, a methyl group linked to a sulfonamide group that is part of a ring. This group might contribute to its more negative EBE. Molecule 1 had two aromatic linked rings and a large sidechain off the second ring with three carbonyl groups and an hydroxyl group. Its EBE is similar to molecules 4 and 6.

\subsection{Nondrug-Like Molecules}

The estimated binding energy of the nondrug-like molecules [14] is shown in Figure 13.

\section{Zhao'14 [14] (Figure 10)}

The framework of the Zhao nondrug-like molecules (Figure 10) is two aromatic fused rings with an hydroxyl group off the second ring and a sidechain para to the hydroxyl group, an amide linker, and an aromatic ring with two fluorines

\section{Estimated Binding Energy of Nondrug-like Molecules (kcal/mole)}

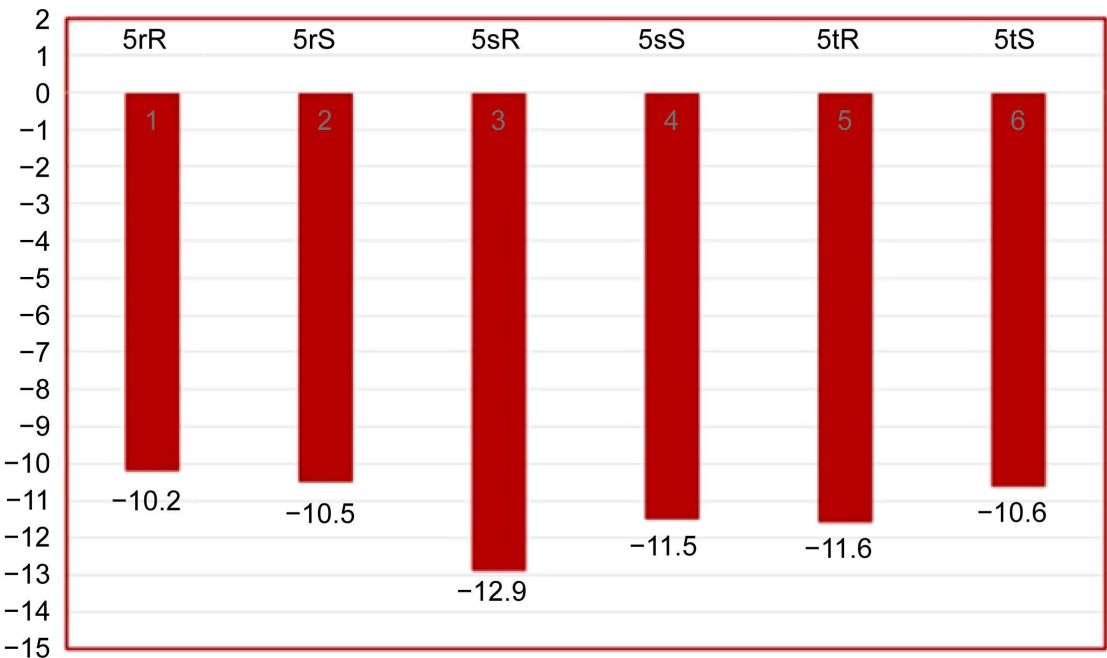

Figure 13. The estimated binding energies of the nondrug-like molecules with 1BIS.pdb. The numbers above the bars correspond to those in Figure 10. 
ortho to each other. It is the sidechain, and an $R$ and $S$ configuration of the three pairs of molecules that make them different. The $5 \mathrm{r} R$ and $5 \mathrm{r} S$ pair had the simplest sidechain and a similar EBE, approximately $-10.3 \mathrm{kcal}$. The other two pairs had a larger sidechain off the second ring than the $5 \mathrm{r}$ pair, and a more negative EBE for the $R$ configuration.

\section{Results of the Estimated Binding Energies with 1BIS.pdb, Mutation Y143R}

As referenced in the HIV Drug Resistance Database [15], mutations of HIV-1 integrase in humans have led to increased resistance to HIV-1 integrase drugs such as raltegravir and elvitegravir. One of the mutations is Y143R. Tyrosine $(\mathrm{Y})$ is also one of the amino acids within an $8 \AA$ radius of the pocket identified as a potential binding site.

Structurally, tyrosine $(\mathrm{Y})$ has a benzene ring. There are six possible hydrogen bond (HB) interactions for tyrosine and also $\pi-\pi$ stacking because of the benzene ring. Arginine $(\mathrm{R})$ can participate in $12 \mathrm{HB}$ interactions but without the phenyl group it loses $\pi-\pi$ stacking capability. (Figure 14)

Tyrosine (Y) (Figure 15) and arginine (R) (Figure 16) are shown within the $8 \AA$ radius of the active site pocket that includes the DDE triad of HIV-1 integrase. The molecules were generated using ICM-Pro, Molsoft, L.L.C.
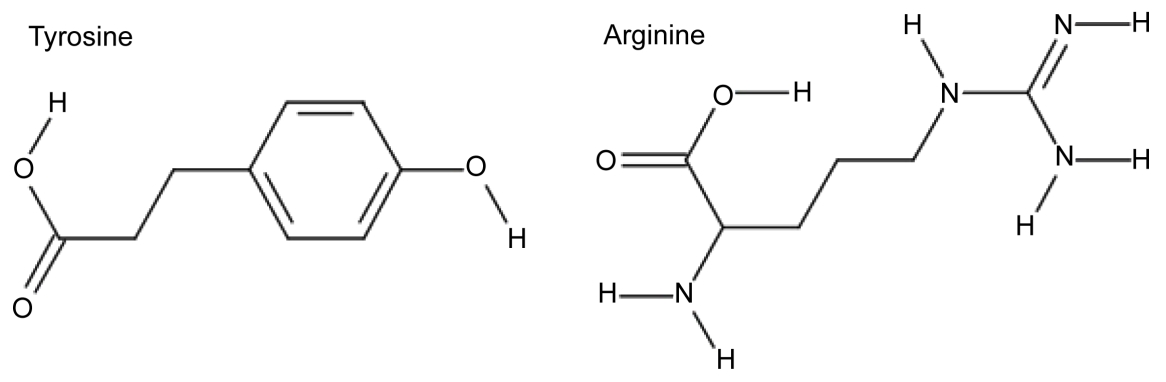

Figure 14. Tyrosine (Y) and arginine (R).

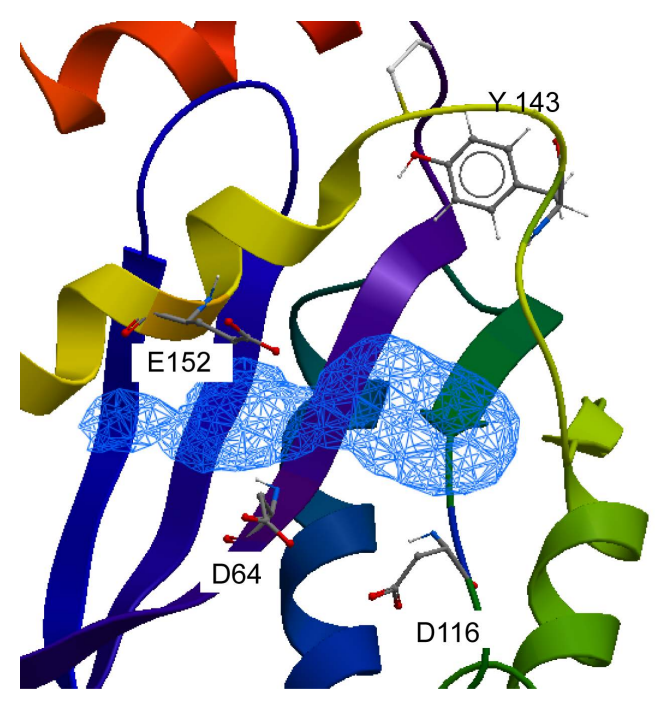

Figure 15. The DDE triad and tyrosine in the active site pocket of 1BIS.pdb. 


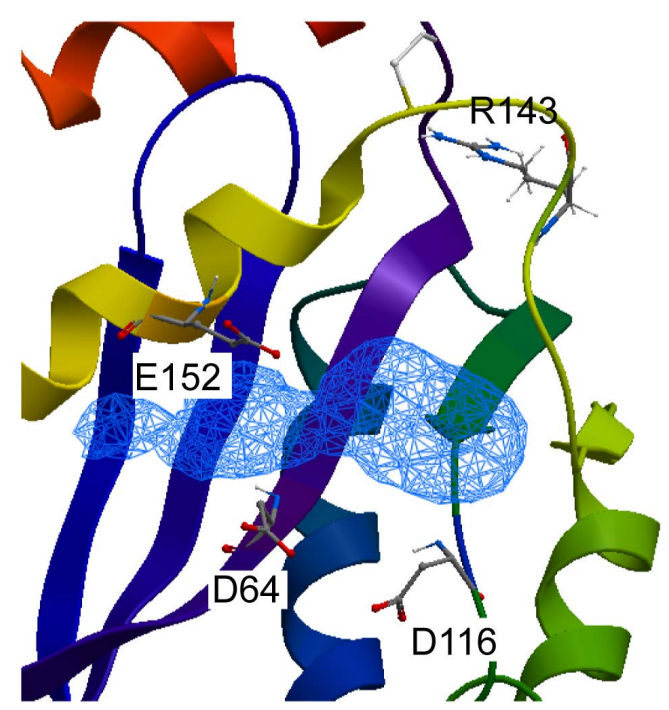

Figure 16. The DDE triad and arginine in the active site pocket of 1BIS.pdb.

\subsection{Drug-Like Molecules}

Approximately 58\% of the drug-like molecules had an EBE that was more negative for the mutant model (shown in black) compared to 1BIS.pdb (shown in green) with $a \geq 1 \mathrm{kcal} /$ mole difference for $33 \%$ of the molecules (Figure 17). There were also $33 \%$ of the drug-like molecules with 1BIS.pdb in which the EBE was more negative than for the mutant model.

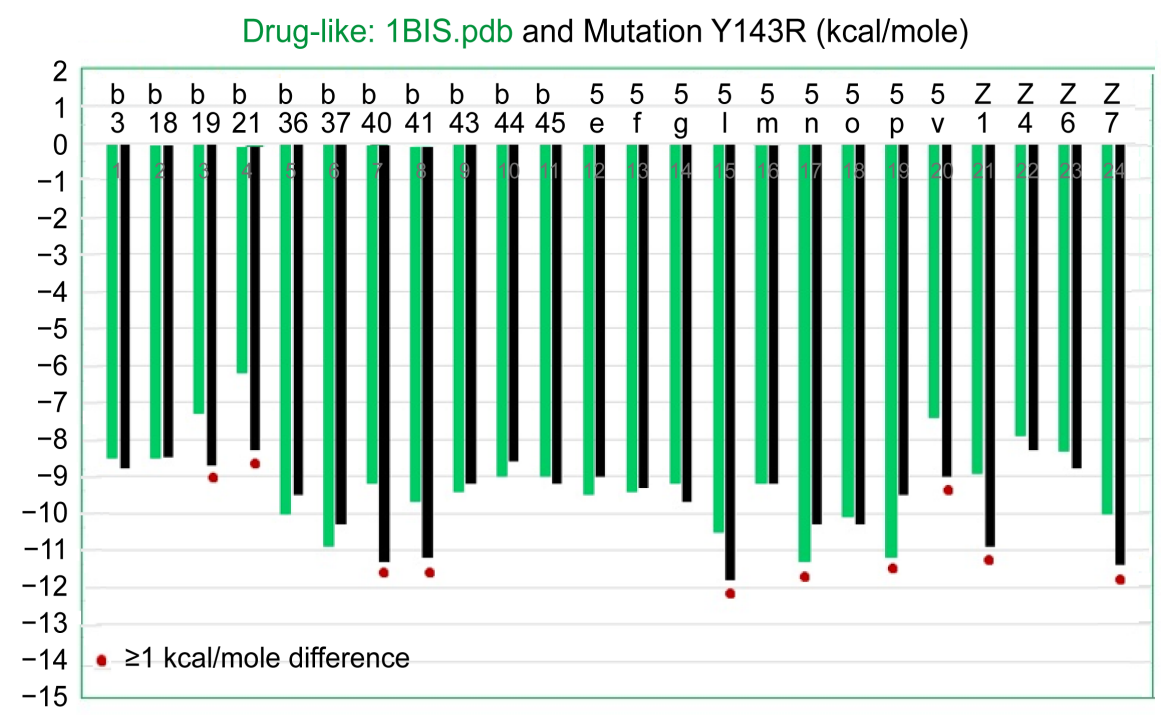

Figure 17. The difference in the EBE between 1BIS.pdb (shown in green) and the mutated protein Y143R (shown in black) with the drug-like molecules. For those where there is $\mathrm{a} \geq 1 \mathrm{kcal} /$ mole difference they are marked with $\bullet$.

\subsection{Nondrug-Like Molecules}

For the nondrug-like molecules, there were four molecules with tighter binding with the mutant model-the $5 \mathrm{r}$ and $5 \mathrm{t}$ molecules $-R$ and $S$ configuration (Figure 18). However, for $5 \mathrm{~s} R$ and $5 \mathrm{~s} S$ there was tighter binding wth 1BIS.pdb. 


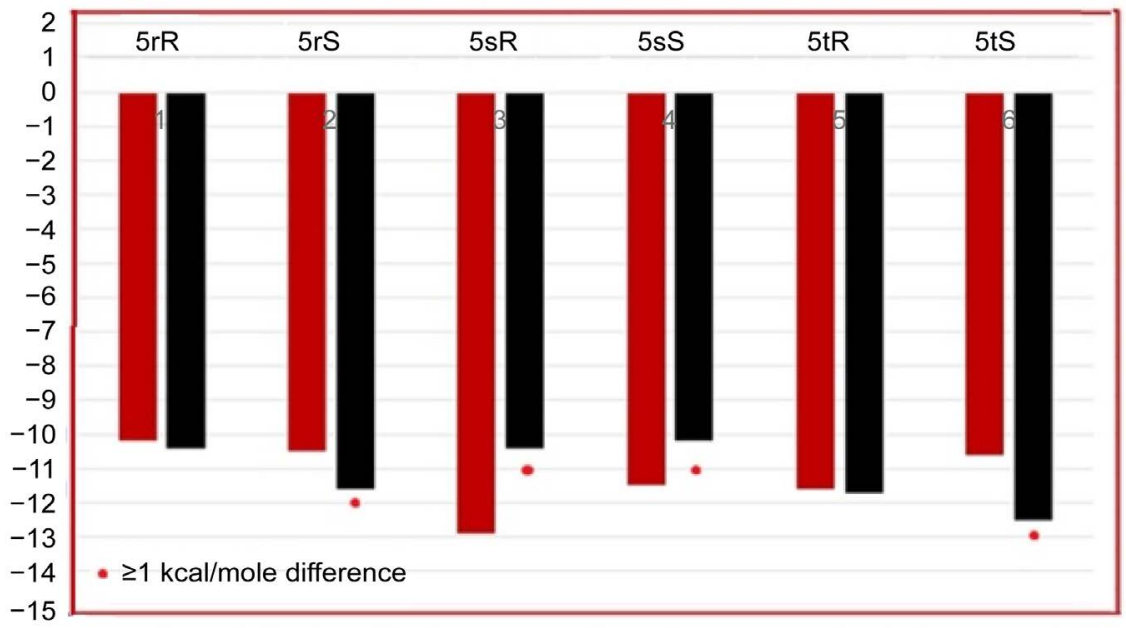

Figure 18. The difference in the EBE between 1BIS.pdb (shown in red) and the mutant model Y143R (shown in black), for the nondrug-like molecules. For those where there is $\mathrm{a} \geq 1 \mathrm{kcal} / \mathrm{mole}$ difference they are marked with $\bullet$.

\section{Results of the Estimated Binding Energies with 1BIS.pdb, Mutation N155H}

This mutation is also referenced in the HIV Drug Resistance Database [15] and has led to increased resistance of the HIV-1 integrase drugs raltegravir and elvitegravir. Asparagine $(\mathrm{N})$ is also one of the amino acids within an $8 \AA$ radius of the pocket identified as a potential binding site.

Structurally, the R group of asparagine $(\mathrm{N})$ has an amide group. There are 11 possible $\mathrm{HB}$ interactions for asparagine. The $\mathrm{R}$ group of histidine $(\mathrm{H})$ is a polar basic group, an imidazole ring; there are nine possible $\mathrm{HB}$ interactions for histidine plus $\pi-\pi$ stacking with the imidazole ring (Figure 19).

Asparagine (N) (Figure 20) and histidine (Figure 21) are shown within the $8 \AA$ radius of the active site pocket that includes the DDE triad. The figures were generated using ICM-Pro, Molsoft, L.L.C.

\subsection{Drug-Like Molecules}

Approximately $46 \%$ of the drug-like molecules had an EBE that was more negative with the mutant model than with 1BIS.pdb (Figure 22). There was a $\geq 1$<smiles>CCCCCCCCCCCC(=O)O[TlH]</smiles><smiles>NC(Cc1cnc[nH]1)C(=O)O</smiles>

Figure 19. Asparagine and histidine. 


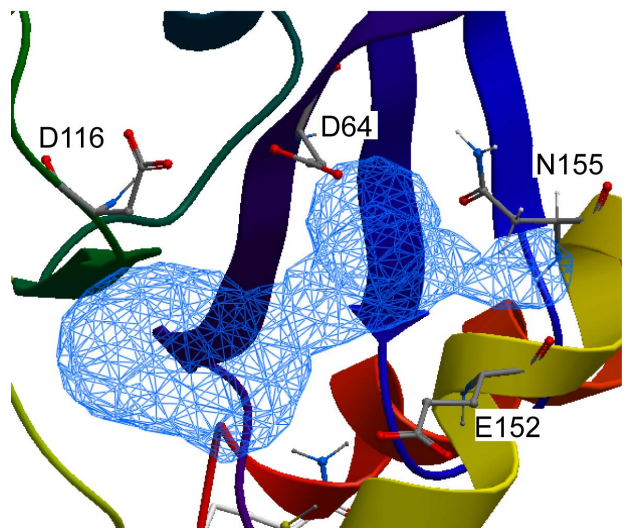

Figure 20. The DDE triad and asparagine in the active site pocket of 1BIS.pdb.

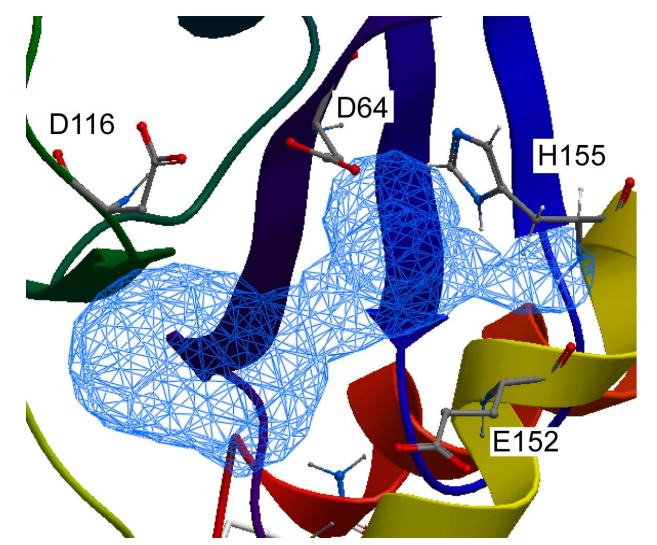

Figure 21. The DDE triad and histidine in the active site pocket of 1BIS.pdb.

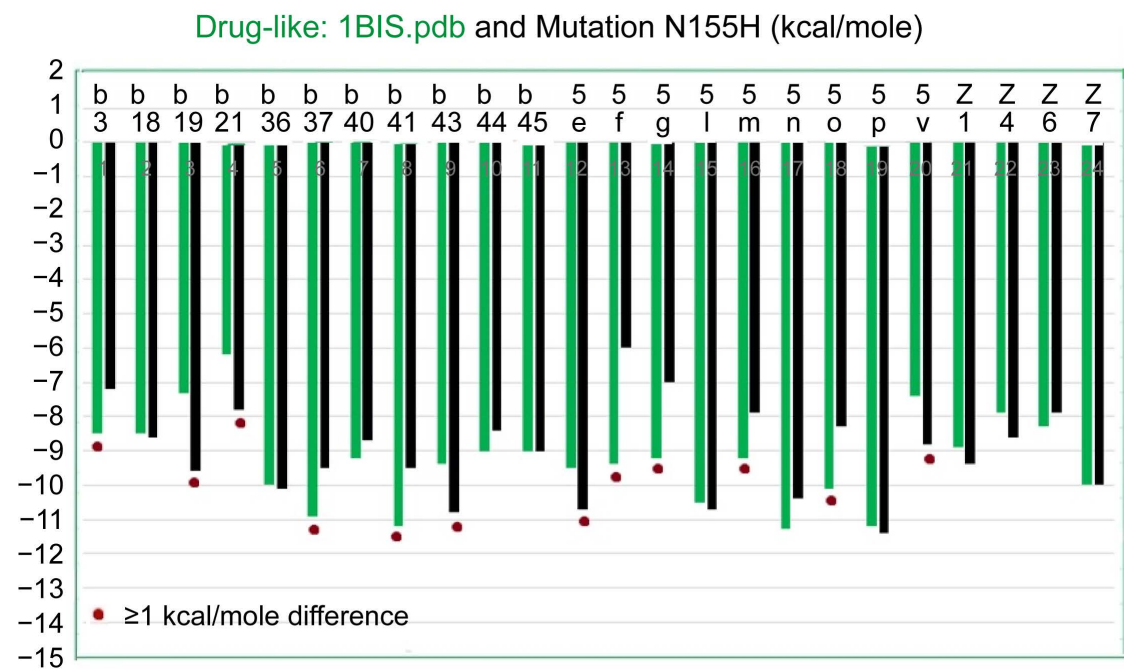

Figure 22. The difference in the EBE between 1BIS.pdb (shown in green) and the mutant model $\mathrm{N} 155 \mathrm{H}$ (shown in black) for the drug-like molecules. For those where there is a $\geq 1$ $\mathrm{kcal} / \mathrm{mole}$ difference they are marked with $\bullet$.

$\mathrm{kcal} /$ mole difference for approximately $21 \%$ of the molecules. There were also approximately $46 \%$ of the drug-like molecules with $1 \mathrm{BIS} . \mathrm{pdb}$ with a more negative EBE than the mutant model; $29 \%$ had a $\geq 1 \mathrm{kcal} /$ mole difference (Figure 22). 


\subsection{Nondrug-Like Molecules}

In four of the six molecules 1BIS.pdb had a more negative EBE: $5 \mathrm{r} S, 5 \mathrm{~s} R, 5 \mathrm{~s} S$, and $5 \mathrm{t} R$. Two molecules had a more negative EBE with the mutant model: $5 \mathrm{r} R$ and $5 \mathrm{t} S$ (very slight). There appears to be no structural pattern to tighter binding in the nondrug-like group. In one molecule, $5 \mathrm{~s} R$, there was a $\geq 1 \mathrm{kcal} / \mathrm{mole}$ difference with 1BIS.pdb (Figure 23).

Nondrug-like: 1BIS.pdb and Mutation N155H (kcal/mole)

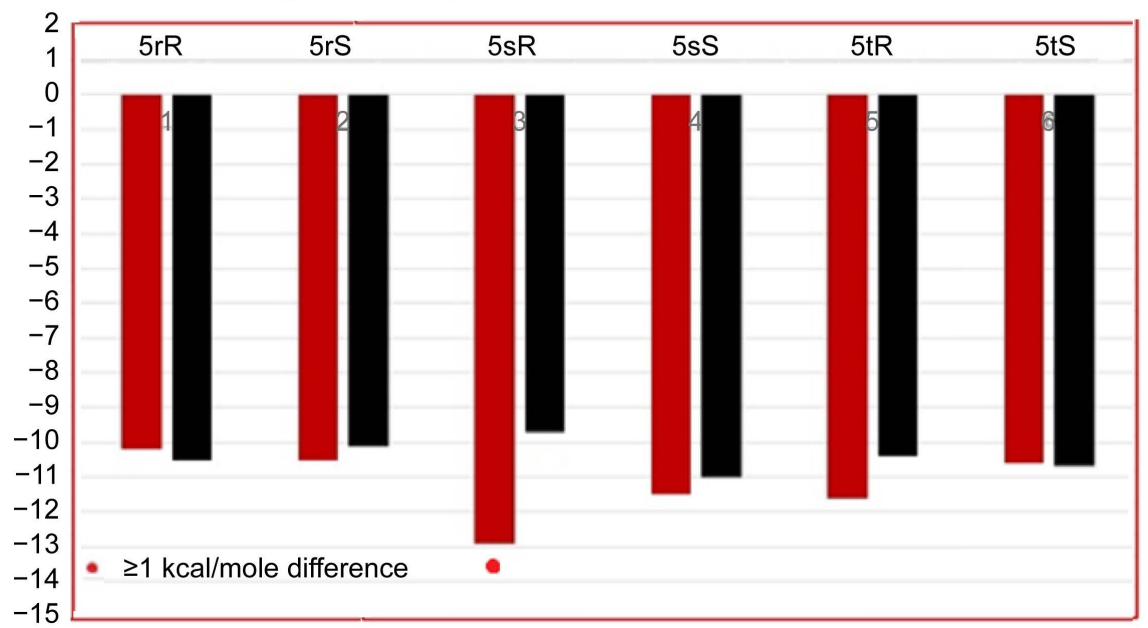

Figure 23. The difference in the EBE using 1BIS.pdb (shown in red) and the mutant model N155H (shown in black) for the nondrug-like molecules.

\section{Discussion}

\subsection{BIS.pdb}

Though drug-like characteristics as defined by Lipinski's "Rule of Five" were introduced for predicting oral bioavailability, the rules were used to classify 30 potential inhibitors of 1BIS.pdb into two groups. The goal was to examine the estimated binding energy of the two groups with 1BIS.pdb and two mutant models of the protein.

The nondrug-like molecules with 1BIS.pdb generally had a more negative EBE $(-12.9$ to -10.2$)$, that is, tighter binding than the drug-like molecules. The binding energy function of ICM-Pro addresses van der Waals interactions of the protein/solvent/ligand, free energy changes when the drug/protein complex forms, hydrogen bonding interactions, hydrophobic free energy gain, desolvation energy of hydrogen bond donor-acceptor interactions, and the number of atoms of the drug. The nondrug-like molecules generally have a larger molecular mass, a greater number of hydrogen bond interactions, and a $\log \mathrm{P}$ value that makes them more hydrophobic, factors that will affect their binding to the protein.

There were seven drug-like molecules with EBE $\geq-10 \mathrm{kcal} / \mathrm{mole}$ : Barreca 36 and 37, Zhao 5l, 5n, 5o, and 5p, and Zhuang 7. Barreca 36 and 37 were similar in structure except Barreca 37 had a fluorine on the first ring, and a more negative EBE than Barreca 36. Both of these had a sidechain off the indole group with two 
carbonyl groups and an ethoxide group to contribute to additional interactions. All of the Zhao molecules had the same basic structure except for a sidechain off the second ring. The sidechain of the four Zhao molecules (51, 5n, 5o, and 5p) was large compared to the other Zhao molecules and could contribute to hydrophobic (5-carbon extension) or hydrogen bond ( $-\mathrm{NH}_{2}$ group, 2-carbon sidechain plus an hydroxyl group, 2-carbon extension plus an ester) interactions with the protein and therefore tighter binding. The structure of Zhuang 7 was similar to the other Zhuang molecules except there was a sidechain with a cyclic sulfonamide group. The number of HBA for the Zhuang 7 molecule was 10 and HBD, one, so there were more increased possibilities for hydrogen bond interactions.

\subsection{Mutant Model, Y143R}

There were structural considerations for mutation of tyrosine $(\mathrm{Y})$ to arginine $(\mathrm{R})$ that could affect the binding of the drug-like molecules in the active site. Tyrosine has six possible HB interactions and a benzene ring that can participate in $\pi$ $-\pi$ stacking, a hydrophobic interaction. The change to arginine increased the number of HB possibilities to 12: five HBA and seven HBD, but with loss of $\pi-$ $\pi$ stacking without the benzene ring. Approximately $58 \%$ of the drug-like molecules had a more negative EBE with the mutant model and there was a $\geq 1$ $\mathrm{kcal} /$ mole difference for $33 \%$ of the molecules. Narrowing that group of molecules to an $\mathrm{EBE} \geq-10.5 \mathrm{kcal} /$ mole there were five drug-like molecules: Barreca 40 and 41, Zhao 5l, Zhuang 1 and 7. There were a total of eight possible HB interactions for Barreca 40,41, and Zhuang 1, seven for Zhao 5l, and eleven for Zhuang 7. However, there were three other molecules for which there were ten possible $\mathrm{HB}$ interactions and two of those, Zhao $5 \mathrm{~m}$ and $5 \mathrm{p}$, had a $\geq 1 \mathrm{kcal} / \mathrm{mole}$ difference and a more negative EBE with 1BIS.pdb.

All of the nondrug-like molecules had at least 13 possible HB interactions. Four of the molecules had a tighter binding with the mutant model but only two, Zhao $5 \mathrm{r} S$ and $5 \mathrm{t} S$, had a $\geq 1 \mathrm{kcal} /$ mole difference between 1BIS.pdb and the mutant model. There were also two molecules, Zhao $5 \mathrm{~s} R$ and $5 \mathrm{~s} S$, where the binding was tighter with $1 \mathrm{BIS}$.pdb with a $\geq 1 \mathrm{kcal} /$ mole difference. Again, there did not appear to be a structural connection for tighter binding based on HB interactions.

\subsection{Mutant Model, N155H}

Asparagine (N) has an amide group and six HBA and five HBD. Histidine's $\mathrm{R}$ group is an imidazole ring that can participate in $\pi-\pi$ stacking, a hydrophobic interaction. It also has five HBA and four HBD. $21 \%$ of the drug-like molecules had a $\geq 1 \mathrm{kcal} /$ mole difference between 1BIS.pdb and the mutant model with a more negative EBE for the mutant model. There were only two of those molecules, Barreca 43 and Zhao 5e, where the EBE was $\geq-10.8 \mathrm{kcal} / \mathrm{mole}$. Both molecules could participate in hydrophobic interactions such as $\pi-\pi$ stacking with the imidazole ring of histidine because of the presence of single and fused rings on the two molecules. Zhao 5e had one more ring than Barreca 43 but this did 
not contribute to tighter binding with the mutant model. They each had at least one fluorine plus six HBA and three and two HBD for Zhao 5e and Barreca 43, respectively. However $29 \%$ of the molecules had a $\geq 1 \mathrm{kcal} / \mathrm{mole}$ difference between 1BIS.pdb and the mutant model with tighter binding for 1BIS.pdb. Two of those molecules had a $\geq-10.9 \mathrm{kcal} / \mathrm{mole}$ EBE: Barreca 37 and Barreca 41 . Both of the molecules had a ring with a fluorine, linker, two fused rings and a sidechain. Barreca 37 also had a chlorine off the fused ring. They differed somewhat in their sidechains but their EBE was similar.

With two exceptions, $5 \mathrm{r} R$ and $5 \mathrm{t} S$, the nondrug-like molecules had tighter binding with 1BIS.pdb. Structurally one was an $R$ configuration and the other $S$ and there was only one more $\mathrm{HB}$ interaction for $5 \mathrm{t} S$. These differences had a minor impact on the EBE of the drug with the mutant model. There was one molecule, $5 \mathrm{~s} R$, with a $\geq 1 \mathrm{kcal} /$ mole difference between $1 \mathrm{BIS}$.pdb and the mutant model with tighter binding with 1BIS.pdb. The EBE with 1BIS.pdb was -12.9 $\mathrm{kcal} / \mathrm{mole}$ and $-9.8 \mathrm{kcal} /$ mole with the mutant model.

\section{Conclusions}

Do the molecules with tighter binding, with either of the two mutant models, share structural characteristics that might be important when designing drugs for HIV-1 integrase? To answer the question, the structure of the drug-like molecules was considered when there was a $\geq 1 \mathrm{kcal} /$ mole difference between $1 \mathrm{BIS}$. $\mathrm{pdb}$ and either of the two mutant models. The two mutations, however, are only two of a number of HIV-1 integrase mutations that have led to increased resistance of HIV-1 integrase drugs such as raltegravir and elvitegravir [15].

The drug-like molecules were the following: Barreca 19, 21, 40, 41, and 43; Zhao 5e, 5l, and 5v; and Zhuang 1 and 7. To address the structural characteristics that the 10 molecules share in common, a pharmacophore (Figure 24) was developed using a 3D pharmacophoric potential implemented on a grid [22]. The IUPAC defines a pharmacophore as "an ensemble of steric and electronic

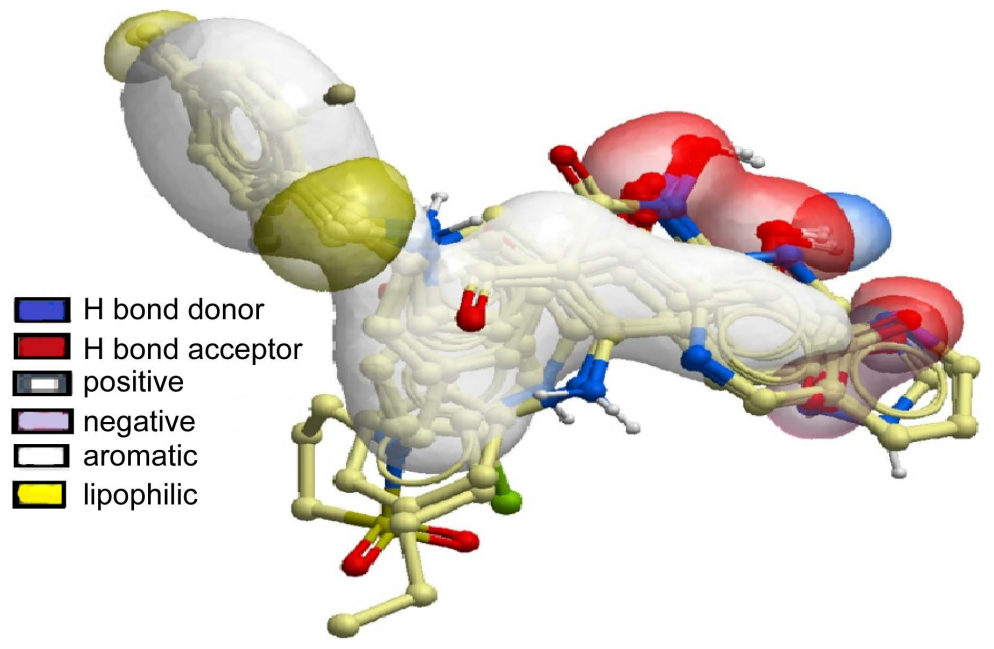

Figure 24. Pharmacophore developed using atomic property fields. The figure was computationally generated by Andy Orry, Molsoft, L.L.C. 
features that is necessary to ensure the optimal supramolecular interactions with a specific biological target and to trigger (or block) its biological response" [23]. Using the Atomic Property Fields (APF) developed by Molsoft, L.L.C. [22] seven properties are assigned from empiric physico-chemical components [22]: hydrogen bond donors and acceptors, $\mathrm{sp}^{2}$ hybridization, lipophilicity, size, electropositive/negative, and charge. The structural properties of the pharmacophore that contribute to interactions between a drug and active site amino acids are displayed in Figure 24 .

The most obvious feature of the pharmacophore is the aromaticity of the rings (shown in white). All of the molecules had some combination of single aromatic rings and/or two fused rings-a common feature in HIV-1 integrase drugs [24]. The aromaticity allows for $\pi-\pi$ stacking with amino acids in the active site. There were a greater number of hydrogen bond acceptors (shown in red), than hydrogen bond donors (shown in blue) for the 10 molecules. The average was six HBA and $2 \mathrm{HBD}$. Hydrophobic/lipophilic areas (yellow) are shown by the presence of fluorine atoms on the molecules, also present on the newest HIV-1 integrase drug, Doultegravir [24]. The aromatic rings are also considered hydrophobic. The hydrophobicity of a molecule is viewed as the driving force for the binding of a protein and a potential drug [25] because water molecules are displaced (desolvation) around hydrophobic surfaces. Increasing the hydrophobicity of the drug permits better binding in hydrophobic pockets; this results in a free energy gain. Charged areas on a potential drug and surrounding amino acids can be $\mathrm{pH}$ dependent with a strong dependence on binding energy because of the changes in proton affinity of ionizable groups [26].

When drugs are designed, Lipinski's Rule of Five should be considered for better bioavailability, that is, the importance of an unchanged drug reaching the systemic circulation. Intermolecular forces, such as hydrogen bonding, hydrophobic interactions, and charge-related bonding between a molecule and receptor can contribute to a more negative estimated binding energy. To minimize the side effects of a molecule, the lowest concentration of the molecule resulting in a physiological response in the active site is paramount. In the case of HIV-1 integrase, the goal of the molecule-receptor interaction is to prevent integration of viral DNA into host DNA.

\section{Acknowledgements}

J.B.E. thanks her administrators for yearly support of the ICM-Pro license. Thank you to Andy Orry, Molsoft, L.L.C., for providing the 2D ligand interaction figure and the pharmacophore.

\section{References}

[1] Centers for Disease Control and Prevention (2010) National Center of Health Statistics. https://www.cdc.gov/nchs/healthy_people/hp2020.htm

[2] Centers for Disease Control and Prevention (2016). https://www.cdc.gov/hiv/basics/statistics.html 
[3] Jaskolski, M., Alexandratos, J.N., Wlodawer, A. and Bujacz, G. (2011) Structural Studies of Retroviral Integrases. In: Neamati, N., Ed., HIV-1 Integrase: Mechanism and Inhibitor Design, John Wiley \& Sons, Inc., Hoboken, 35-49. https://doi.org/10.1002/9781118015377.ch4

[4] Steigbigel, R.T., Coooper, D.A., Kumar, P.N., Eron, J.E., Schechter, M., Markowitz, M., Loutfy, M.R., Lennox, J.L., Gatell, J.M., Rockstroh, J.K., Katlama, C., Yeni, P., Lazzarin, A., Clotet, B., Zhao, J., Chen, J., Ryan, D.M., Rhodes, R.R., Killar, J.A., Gilde, L.R., Strohmaier, K.M., Meibohm, A.R., Miller, M.D., Hazuda, D.J., Nessly, M.L., DiNubile, M.J., Isaacs, R.D., Nguyen, B.-Y. and Teppler, H. (2008) Raltegravir with Optimized Background Therapy for Resistant HIV-1 Infection. New England Journal of Medicine, 359, 339-354. https://doi.org/10.1056/NEJMoa0708975

[5] Sax, P.E., DeJesus, E., Mills, A., Zolopa, A., Cohen, C., Wohl, D., Gallant, J., Liu, H.C., Zhong, L., Yale, K., White, K., Kearney, B.P., Szwarcberg, J., Quirk, E. and Cheng, A.K. (2012) Co-Formulated Elvitegravir, Cobicistat, Emtricitabine, and Tenofovir versus Co-Formulated Efavirenz, Emtricitabine, and Tenofovir for Initial Treatment of HIV-1 Infection: a Randomised, Double-Blind, Phase 3 Trial, Analysis of Results after 48 Weeks. The Lancet, 379, 2439-2448.

[6] Hare, S., Metifiot, M., Jaxa-Chamiec, A., Pommier, Y., Hughes, S.H. and Cherepanov, P. (2011) Structural and Functional Analyses of the Second-Generation Integrase Strand Transfer Inhibitor Dolutegravir. Molecular Pharmacology, 80, 565572. https://doi.org/10.1124/mol.111.073189

[7] HIV-1 Life Cycle.

https://cellandbioscience.biomedcentral.com/articles/10.1186/2045-3701-2-32

[8] Johnson, B.C., Metifiot, M., Pommier, Y. and Hughes, S.H. (2012) Molecular Dynamics Approaches Estimate the Binding Energy of HIV-1 Integrase Inhibitors and Correlate with in Vitro Activity. Antimicrobial Agents and Chemotherapy, 56, 411419. https://doi.org/10.1128/AAC.05292-11

[9] 1BIS.pdb. http://www.rcsb.org/pdb/explore/explore.do?structureId=1bis

[10] Engelman, A. and Craigie, R. (1992) Identification of Conserved Amino Acid Residues Critical for Human Immunodeficiency Virus Type 1 Integrase Function in $\mathrm{Vi}$ tro. Journal of Virology, 66, 6361-6369.

[11] ICM-Pro, Molsoft, L.L.C. http://www.molsoft.com/

[12] Katzman, M. and Katz, R.A. (1999) Substrate Recognition by Retroviral Integrases. Advances in Virus Research, 52, 371-395.

[13] Lipinski, C.A. (2004) Lead- and Drug-like Compounds: The Rule-of-Five Revolution. Drug Discovery Today: Technologies, 1, 337-341.

[14] Zhao, X.Z., Smith, S.J., Métifiot, M., Marchand, C., Boyer, P.L., Pommier, Y., Hughes, S.H. and Burke, T.R. (2014) 4-Amino-1-hydroxy-2-oxo-1,8-naphthyridineContaining Compounds Having High Potency against Raltegravir-Resistant Integrase Mutants of HIV-1. Journal of Medicinal Chemistry, 57, 5190-5202. https://doi.org/10.1021/jm5001908

[15] HIV Drug Resistance Database. https://hivdb.stanford.edu/

[16] Neves, M.A., Totrov, M. and Abagyan, R. (2012) Docking and Scoring with ICM: The Benchmarking Results and Strategies for Improvement. Journal of ComputerAided Molecular Design, 26, 675-686. https://doi.org/10.1007/s10822-012-9547-0

[17] Barreca, M.L., Ferro, S., Rao, A., De Luca, L., Zappalà, M., Monforte, A.M., Debyser, Z., Witvrouw. M. and Chimirri, A. (2005) Pharmacophore-Based Design of HIV-1 Integrase Strand-transfer Inhibitors. Journal of Medicinal Chemistry, 48, 70847088 . 
[18] Zhuang, L., Wai, J., Embrey, M.W. and Young, S.D. (2013) Design and Synthesis of 8-Hydroxy-[1,6] Naphthyridines as Novel Inhibitors of HIV-1 Integrase in Vitro and in Infected Cells. Journal of Medicinal Chemistry, 46, 453-456. https://doi.org/10.1021/jm025553u

[19] Crystal Structural Database. https://www.ccdc.cam.ac.uk/solutions/csd-system/components/csd/

[20] Krystek, S. (2012) Senior Principal Scientist, Bristol-Myers Squibb. Personal communication.

[21] Bemis, G.W. and Murcko, M.M. (1996) The Properties of Known Drugs. 1. Molecular Frameworks. Journal of Medicinal Chemistry, 39, 2887-2893.

[22] Totrov, M. (2008) Atomic Property Fields: Generalized 3D Pharmacophoric Potential for Automated Ligand Superposition, Pharmacophore Elucidation and 3D QSAR. Chemical Biology \& Drug Design, 71, 15-27. https://doi.org/10.1111/j.1747-0285.2007.00605.x

[23] Wermuth, C.G., Ganellin, C.R., Lindberg, P. and Mitscher, L.A. (1998) Glossary of Terms Used in Medicinal Chemistry (IUPAC Recommendations 1998). Pure and Applied Chemistry, 70, 1129-1143. https://doi.org/10.1351/pac199870051129

[24] Libre, J.M., Pulido, F., Garcia, F., Deltoro, M.G., Blanco, J.L. and Delado, R. (2015) Genetic Barrier to Resistance for Dolutegravir. AIDS Reviews, 17, 56-64.

[25] Biela, A., Nadief, N.N., Betz, M., Heine, A., Hangauer, D. and Klebe, G. (2013) Dissecting the Hydrophobic Effect on the Molecular Level: The Role of Water, Enthalpy, and Entropy in Ligand Binding to Thermolysin. Angewandte Chemie International Edition, 52, 1822-1828. https://doi.org/10.1002/anie.201208561

[26] Murphy, K.P. (1999) Predicting Binding Energetics from Structure: Looking Beyond $\Delta \mathrm{G}^{0}$. Medicinal Research Reviews, 19, 333-339.

https://doi.org/10.1002/(SICI)1098-1128(199907)19:4<333::AID-MED6>3.0.CO;2-5 


\section{Nomenclature}

HIV-1: human immunodeficiency virus

RT: reverse transcriptase

RNA: ribonucleic acid

DNA: deoxyribonucleic acid

D: amino acid, aspartic acid

E: amino acid, glutamic acid

Y143R: amino acid number 143, tyrosine (Y), is mutated to arginine (R)

$\mathrm{N} 155 \mathrm{H}$ amino acid number 155 asparagine $(\mathrm{N})$, is mutated to histidine

EBE: estimated binding energy

HBA: hydrogen bond acceptor

HBD: hydrogen bond donor

NTD: amino-terminal domain, amino acids 1-50

CCD: core catalytic domain, amino acids 50-212,

CTD: carboxyl-terminal domain, amino acids 212-288

APF: Atomic Property Fields

Submit or recommend next manuscript to SCIRP and we will provide best service for you:

Accepting pre-submission inquiries through Email, Facebook, LinkedIn, Twitter, etc. A wide selection of journals (inclusive of 9 subjects, more than 200 journals)

Providing 24-hour high-quality service

User-friendly online submission system

Fair and swift peer-review system

Efficient typesetting and proofreading procedure

Display of the result of downloads and visits, as well as the number of cited articles

Maximum dissemination of your research work

Submit your manuscript at: http://papersubmission.scirp.org/

Or contact abb@scirp.org 